\title{
A rare case of perineal endometriosis with anal sphincter involvement
}

\author{
Bhadana Priyanka, Abha Kiran*, Veena Ganju Malla
}

\begin{abstract}
Department of Obstetrics and Gynecology, Atal Bihari Vajpayee Institute of Medical Sciences and Dr Ram Manohar
\end{abstract} Lohia Hospital, New Delhi, India

Received: 07 November 2019

Revised: 27 January 2020

Accepted: 01 February 2020

\author{
*Correspondence: \\ Dr. Abha Kiran, \\ E-mail: kiran.abha05@gmail.com
}

Copyright: (c) the author(s), publisher and licensee Medip Academy. This is an open-access article distributed under the terms of the Creative Commons Attribution Non-Commercial License, which permits unrestricted non-commercial use, distribution, and reproduction in any medium, provided the original work is properly cited.

\begin{abstract}
Perineal endometriosis is a rare entity which can be explained by direct implantation of endometriotic cells over the fresh episiotomy wound and subsequent development of scar endometriosis. Perineal scar endometriosis incidence is reported to be $0.3 \%$ to $1 \%$. 28 years old, P1L1, presented with pain and swelling near episiotomy site which is associated with menstruation. Examination during menstruation revealed swelling was tender, erythematous and slightly increased in size. Clinical diagnosis of scar endometriosis was made after clinical examination. Mass excised and sent for histopathological examination. Although diagnosis essentially remains clinical, preoperative evaluation with perineal ultrasound and MRI was performed. Wide local excision remains treatment of choice and follow up for recurrence is recommended. Histopathological examination is obligatory to exclude rare possibility of malignant changes.
\end{abstract}

Keywords: Dyspareunia, Dysmenorroea, Endometriosis, Perineal endometriosis, Scar endometriosis, Wide local excision

\section{INTRODUCTION}

Perineal endometriosis is a rare entity which can be explained by direct implantation of endometriotic cells over the fresh episiotomy wound and subsequent development of scar endometriosis. Perineal scar endometriosis incidence is reported to be $0.3 \%$ to $1 \%{ }^{1}$

\section{CASE REPORT}

A 28 year, P1L1 7 years after her last delivery reported in gynecology OPD with complains of cyclic pain and swelling in the perineal region. There was associated dyspareunia which gradually increased in intensity and duration for past 10 months. Pain in the perineum was localized without any radiation and used to become most intense just before and immediately after the onset of menstrual bleeding. Patient was symptom free during rest of the month. She was fully continent with bowel and bladder function. There was no associated history of fever, abnormal discharge per vaginum.

She delivered her first child 7 years back with right mediolateral episiotomy followed by interval IUCD insertion as contraceptive.

Her menstrual history was normal, and her last menstrual period was 12 days back.

On examination, her vitals were within normal range and systemic examination did not reveal any abnormality.

On local inspection, previously healed episiotomy scar was seen with a swelling $3 \times 3 \mathrm{~cm}$ near episiotomy site (Figure 1), slightly tender on palpation, and firm to hard in consistency and involving the external anal sphincter. 
She had good sphincter tone on digital rectal examination.

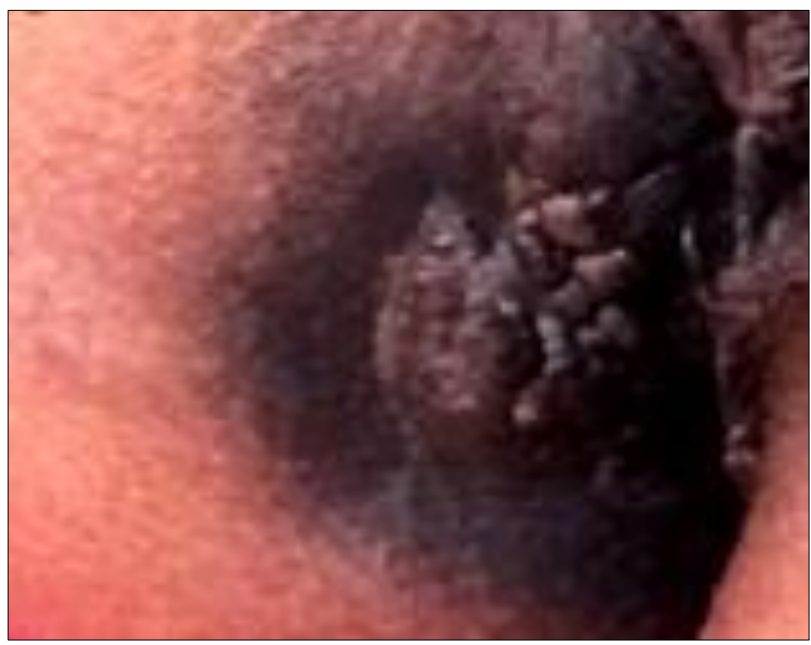

Figure 1: Healed perineal scar with swelling $3 \times 3 \mathrm{~cm}$.

Transperineal ultrasound revealed a heterogeneous echogenic mass of $3.5 \times 2.7 \mathrm{~cm}$ with an inflammatory zone. MRI showed $3.5 \times 2.8 \mathrm{~cm}$ lobulated lesion in perianal region with subtle fat stranding and oedema seen. Her biochemical parameters were all in normal limit. Proctosigmoidoscopy findings were normal

\section{Management}

Endometriotic scar excision was done along with partial reconstruction of external sphincter. Examination under anaesthesia showed presence of a hard-indurated mass about $3.5 \times 2.5 \mathrm{~cm}$ in right lateral position associated with healed episiotomy scar and involvement of external anal sphincter muscle fibres.

\section{Procedure}

Patient was put in lithotomy position. A radial incision was given and whole of the endometriotic mass extending into ischiorectal fossa was dissected out. The excision extended medially and part of anal sphincter was also removed. Dissection was done between rectum and posterior vaginal wall. Same side sphincter ani muscles were strengthened. A closed suction drain was placed in right ischiorectal fossa. The excised specimen showed characteristic dark-brown chocolate colored small cysts.

\section{Histopathological examination}

Excised endometriotic tissue was sent for histopathological examination which confirmed it to be endometriosis with invasion into anal sphincter muscles.

The postoperative recovery remained uneventful and was started on Dienogest $2 \mathrm{mg}$ once daily for one month. Post-operative healed perineal wound (Figure 2) was non tender and healthy. She had good resting and squeezing tone after one-month post-surgery.

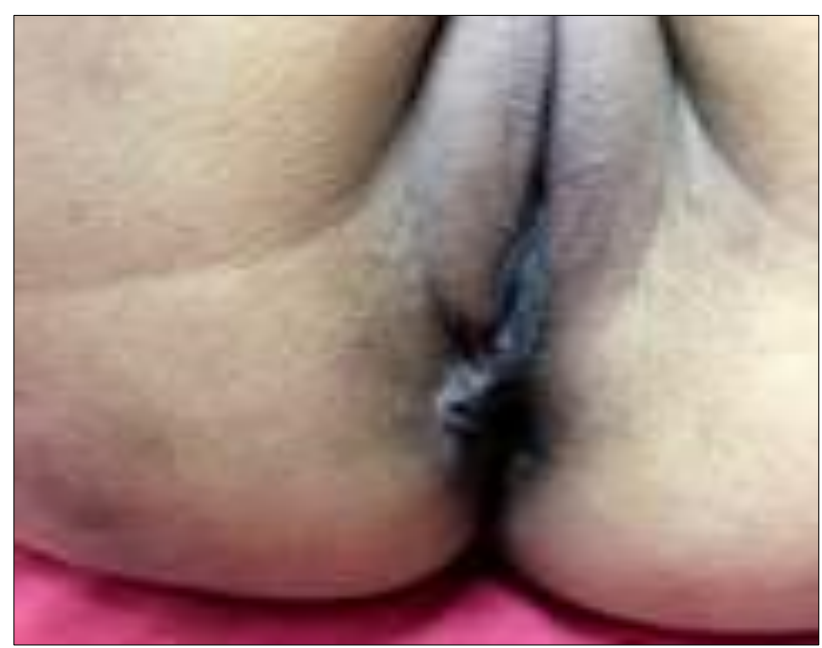

Figure 2: Postoperative healed perineal wound.

\section{DISCUSSION}

Endometriosis was first described by Rokitansky in 1860 as the presence and proliferation of the endometrium outside the uterine cavity, commonest site being the pelvis. ${ }^{2}$ Perineal endometriosis was first reported in 1923 Scheckele, and first case of ano-perineal endometriosis of anal canal by De La Cruz in $1968 .^{3}$ The etiology and pathogenesis of endometriosis are complex and still incompletely understood.

\section{So many theories have been developed}

- Implantation theory

- Coelomic metaplasia

- Transplantation of exfoliated endometrium. ${ }^{4}$

Altered immunology Transplantation theory is actually derived from the first theory (implantation theory). During vaginal delivery; viable endometrial cells become implanted in the perineum, including the site of episiotomy and result in endometriotic esions. However, perineal endometriosis without history of delivery cannot be explained by transplantation theory. Lymphatic dissemination theory has been hypothesized for such cases. As there are rich lymphatic communications between uterus, cervix, vaginal and perineum, endometrial tissues can be transported by lymphatic routes and result in perineal endometriosis. Contact of endometrial tissue with perineal injury often occurs during vaginal delivery, but the incidence of perineal endometriosis is rare.

\section{The reasons for rare incidence may include the following}

- Bacteria existing in the perineal wound which can cause infection or even necrosis of the local tissues. 
The infection and necrosis are not appropriate for transplanted endometrial cells to live

- After delivery, the level of estrogen decreases, which also makes the growth of transplanted endometrial cells difficult.

Usually a classical triad of cyclic pain, perineal mass and previous episiotomy or tear is sufficient to clinch the diagnosis in scar endometriosis. Differential diagnosis of this entity includes suture granulomas, abscesses, hematomas, chelodid, lipomas, sebaceous cysts, desmoids or malignant tumour. ${ }^{5}$ Fine needle aspiration (FNA) provides a rapid, inexpensive and accurate diagnosis and rules out other differentials; but is stated as controversial by some authors as it might result in new endometriotic implants. ${ }^{6,7}$ Imaging modalities such as ultrasound and MRI are indicated in case of large lesions, anal involvement and surgical planning. MRI is also useful to differentiate it from another lesion like lipoma, abscess. ${ }^{8}$

The treatment of choice is wide resection of the lesion with $1 \mathrm{~cm}$ margin on all sides along with a sphincteroplasty (cases where anal sphincter is involved). ${ }^{9}$ Incomplete excision can lead to recurrence. Surgical method has an advantage of providing sample for biopsy to confirm diagnosis and rule out malignancy. ${ }^{8}$ While malignant transformation is rare, few cases have been reported. ${ }^{10}$ To prevent progressive involvement of the anal sphincter, early diagnosis and treatment is imperative. ${ }^{11}$ Being a rare entity high index of suspicion should be kept diagnosing this entity. As episiotomy is very frequently performed at the time of vaginal delivery, incidence of perineal endometriosis can be reduced by washing the episiotomy wound with normal saline before suturing, avoiding manual uterine exploration and postpartum curettage.

\section{CONCLUSION}

Episiotomy scar endometriosis is essentially a clinical diagnosis. One should keep high index of suspicion when a woman in reproductive age group presents a mass and pain in scar region following an episiotomy. It is best treated with wide local excision. Involvement of anal sphincter should be carefully evaluated (clinically and endo-anal ultrasound) and ruled out before proceeding for surgical treatment. Timely treatment can prevent progressive invasion of anal sphincter and subsequent morbidity. Follow up is essential as recurrence is not uncommon.
Funding: No funding sources

Conflict of interest: None declared

Ethical approval: The study was approved by the Institutional Ethics Committee

\section{REFERENCES}

1. Gauna BRD, Rodriguez D, Cabre S, Callejo J. A Case of Endometriosis in episiotomy scar with anal sphincter involvement. Inter J Clin Med. 2011;2:6246.

2. Al-Jabri K. Endometriosis at caesarian section scar. OMJ. 2009;24:294-5.

3. Laadioui M, Alaoui F, Jayi S, Bouguern H, Chaara H. L'endometriose perineale profonde surcicatriced'episiotomie: A propos d'un cas rare. Pan African Med J. 2013;16:112.

4. Vinatier D, Orazi G, Cosson M, Dufour P. Theories of endometriosis. European Journal of Obstet Gynecol Reprod Biol. 2001;96(1):21-34.

5. Andola US, Andola SK, Sanghvi KJ. FNAC diagnosis of Scar endometriosis: A report of 3 cases with review of literature. J Basic Clin Reprod Sci. 2012;1:62-4.

6. Schoelefield HJ, Sajjad Y, Morgan PR (2002) Cutaneous endometriosis and its association with caesarean section and gynaecological procedures. J Obstet Gynaecol. 2002;22:553-4.

7. Medeiros FC, Calvalcante DM. Fine needle aspiration cytology of scar endometriosis: A study of seven cases and literature review. Diagnos Cytopathol. 2011;39:18-21.

8. Demir M, Yildiz A, Ocal I, Yetimalar MH, Kilic D. Endometriosis in episiotomy scar: A case report. J Cases Obstet Gynecol. 2014;1:8-10.

9. Kang SK, Lee MW, Choi JH, Sung KJ, Moon KC. Cutaneous endometriosis: a combination of medical and surgical treatment. J Dermatolog Treat. 2002; $13: 189-92$.

10. Hitti IF, Glasberg SS, Lubicz S. Clear cell carcinoma arising in extraovarian endometriosis: Report of three cases and review of the literature. Gynecol Oncol. 1990;39:314-20.

11. Jain D. Perineal scar endometriosis: a comparison of two cases. BMJ Case Rep. 2013;29:1.

Cite this article as: Priyanka B, Kiran A, Malla VG. A rare case of perineal endometriosis with anal sphincter involvement. Int J Reprod Contracept Obstet Gynecol 2020;9:1268-70. 